\title{
EL VINO DE LOS HÉROES HOMÉRICOS
}

\author{
The Wine of the Homeric Heroes
}

\author{
M. José García Soler*
}

Recibido el 10 de noviembre de 2010. Aceptado el 30 de diciembre de 2010

\begin{abstract}
Resumen. El vino tiene un importante papel en el mundo idealizado de los héroes homéricos. El poeta ofrece las primeras descripciones de vinos griegos, principalmente procedentes del norte del Egeo, situándolos en contextos muy variados, como centro del banquete, bebida reconstituyente, elemento imprescindible en plegarias y juramentos e incluso símbolo de honor que distingue a los personajes más destacados. Palabras clave: vino; Homero; literatura griega; poesía épica
\end{abstract}

\begin{abstract}
Wine has played an important role in the idealized world of Homeric heroes. The poet made the first descriptions of Greek wines, mainly produced at the North of the Aegean Sea, situating it in a variety of contexts: at the center of a banquet, as a tonic beverage, as an essential element in prayers and oaths, and also as a symbol of the honour that distinguishes the main protagonists.
\end{abstract}

Key Words: Homer; Greek literature; Epic poetry

Los poemas homéricos muestran un mundo idealizado, poblado por seres extraordinarios que llevan a cabo hazañas igualmente extraordinarias. La llíada pone ante nuestros ojos a héroes y dioses involucrados en una guerra ante los muros de Troya a causa de la bella Helena, situándonos por tanto, en un contexto eminentemente bélico. A través de la Odisea asistimos a las vicisitudes que rodean el regreso a su patria de uno de los grandes jefes aqueos, Ulises, un viaje lleno de aventuras y peligros. Sin embargo, en sus dos obras Homero coloca también a sus personajes en un ámbito que tiene mucho que ver con la vida cotidiana de los héroes, distinta de la de los hombres comunes, pero con muchos rasgos comunes con ella. En esta vida heroica el vino, presente con facetas muy variadas, ocupa una posición especial, hasta tal punto que Horacio (Epodos I 19,6) se referirá al poeta llamándolo vinosus Homerus.

El vino constituye, de hecho, uno de los símbolos del estatus del héroe dentro de su comunidad. En los poemas homéricos, donde se muestra una organización social rígidamente jerarquizada, es un privilegio del rey. Tener vino es un signo de riqueza y ofrecerlo con generosidad a un huésped es una muestra de magnificencia y de honor. Por ello, el banquete era una prueba ostensible del poder del jefe y a él podían ser admitidos unos pocos que se distinguían por su actividad política, judicial y sobre todo militar al servicio de la comunidad (Murray 1983a: 260-261; Carlier 1984: 155-157; Alonso Troncoso 1993: 38-39; Andò 2004: 89-90). A estos personajes destacados se destinan las partes más escogidas de los animales sacrificados, el pan más blanco y el vino más dulce. Menelao muestra el hecho de beber el vino a expensas del pueblo como una distinción (II.XVII 250), porque los honores que se reciben en un banquete representan el reconocimiento del valor en el campo de batalla, constituyendo una especie de alabanza pública. Por eso mismo, también en sentido inverso, quien come y bebe bien de la misma manera debe luchar bien y el orden en el combate debe corresponderse con el orden en el banquete. Así, Agamenón afirma el aprecio que tiene a Idomeneo "tanto en el combate y para cualquier empresa, / como en el banquete, cuando el rutilante vino honorífico / los adalides de los argi-

* Universidad del País Vasco, Facultad de Letras. Paseo de la Universidad, n5 5. E-01006 Vitoria-Gasteiz. E-mail: mj.garcia@ehu.es. 
vos mezclan en la cratera» (II. IV 258-260). Por este motivo, mientras los demás beben la ración que se les asigna, la copa de Idomeneo siempre está llena, como la del propio soberano de Micenas, que le insta a que vaya al combate y se comporte según corresponde a tal honor. También Menelao, para animar a los aqueos a combatir para defender el cuerpo de Patroclo, se dirige a ellos con estas palabras: «iVosotros, que junto a los Atridas Agamenón y Menelao bebéis a costa pública y dais señales de orden a las respectivas huestes, y a quienes el honor y la gloria de Zeus acompañan!» (II. XVII 243-251). Paralelamente, constituye un insulto reprochar a un héroe que parezca más interesado en acudir al festín que en combatir o afirmar que no se merece la copa de vino público que bebe con el rey'.

A lo largo de los poemas son frecuentes las representaciones de banquetes y en algunos casos es posible atisbar ya las primeras alusiones a lo que será después el simposio. Se ha discutido mucho sobre si en Homero puede hablarse o no con propiedad de la existencia del sympósion, el segundo momento del banquete, en el que en torno al consumo del vino se realizan actividades variadas como el canto o la práctica de algunos juegos. El término como tal no aparece hasta el siglo VII a. C. con Alceo y Focílides ${ }^{2}$, aunque en Homero -más en la Odisea que en la lliada- encontramos también otras denominaciones que aluden a diversos tipos de banquete, como daís, término relacionado con la idea de distribución, que tiene mucho que ver con la expresión del poder político en el mundo de la épica, y deîpnon, que designa más una comida con fines alimenticios que un festín; también aparecen nombres menos usuales como thalía, eilapíne y éranos, en el que los invitados aportaban algo para la cena (Garzón Díaz 1979: 63. Carlier 1984: 154-155. Rundin 1996: 185-191. Sherratt 2004: 189-191). Algunos autores, entre los que destacan por su influencia P. von der Mühl (1975) y K. Bielohlawek (1940), rechazan por completo la posibilidad de que existiera ya el sympósion en Homero, al aplicar rígidamente las categorias que lo caracterizan en las épocas arcaica y clásica. Sin embargo, M. Vetta (1995: XLII y 1996: 124) observó la existencia de un verso formular que se repite varias veces a lo largo de los poemas y que podría marcar un corte en el desarrollo del banquete: "y después de que hubieron alejado el deseo de comer y beber»3 . Sobre esta base G. Colesanti (1999: 49-51) ha analizado diversas escenas en las que reconoce los rasgos del simposio, todavía integrado en el banquete en sentido propio, ya que quedan aún sobre las mesas los panes y las carnes, a pesar de que los participantes se encuentran ya en el momento dedicado a la bebida (cf. Od. XXII 17-12, 84-86). En opinión de A. Dalby (1996: 102), probablemente el primer testimonio de una reunión de hombres para beber aparte de la comida tiene lugar en el palacio de Alcínoo, rey de los feacios. En el momento en que llega Ulises, llevado por la princesa Nausícaa, los asistentes no están comiendo, sino que ya han pasado al vino y seguirán con él mientras se traen alimentos para el visitante ${ }^{4}$.

También W. Cowski (2002: 628-631) piensa que el simposio aparece en primer lugar en el mundo de los feacios y no en el de los héroes, que celebrarían festines diferentes. Con todo, ha estudiado con especial atención el banquete de los pretendientes de Penélope y ha encontrado en él rasgos propios del simposio, que sin duda debía de ser conocido para el público de Homero. Uno de los más característicos es que todas las actividades simpóticas estaban subordinadas al vino y sus manipulaciones. Los cantos, los juegos, los brindis, todo tenía lugar epidexia, "desde la derecha", exactamente de la misma manera en que se servía el vino a los participantes. W cowski no ve nada semejante en los banquetes heroicos, pero sí lo encuentra en el modo en que es servido el néctar por Hefesto en el banquete de los dioses que Homero representa en el canto I (595-604) de la Ilíada. También ve esta costumbre reflejada en dos momentos del banquete de los pretendientes de Penélope en casa de Ulises, en primer lugar cuando el héroe, disfrazado de mendigo, se acerca a ellos para pedir (XVII 365-367) y en el orden en que se desarrolla el concurso del arco: «Idos, joh amigos!, alzando de izquierda a derecha, / por el orden que sigue el copero al servirnos el vino" (XXI 141-142).

Hay que señalar, sin embargo, que existen algunas diferencias claras entre este simposio homérico y la forma que presenta en las épocas arcaica y clásica. Una de las más notables es que los participantes estaban sentados y no tumbados5, y además se admitía la presencia de mujeres, como sucede en el caso de Arete, la reina de los feacios o de Helena6 y, más raramente, en el de Penélope, la esposa de Ulises. A pesar de ello no participan de la bebida en el banquete, 0

II. IV 340-348, VIII 161-163, 185-190, XII 310-321, XX 83-85.

2 Alceo, fr. 70 Voigt. Focílides, fr. 14 Diels.

3 II. I 469, II 432, VII 323, IX 92, 222, XXIII 57, XXIV 627; Od. I 150, III 67, 473, IV 68, VIII 72, 485, XII 308, XIV 454, XV 143, 303, 501, XVI 55, 480, XVII 99. Cf. Mainardi y Berta 1991: 17; Bianca 2002: 27-28.

4 (Od. VII 136-138, 172-183).

5 II. XIV 238-241, XV 95-100; Od. I 129-131, 144-148, III 388-391, VI 309, VII 169-176, IX 4-10, 556-558 (= X 183-185), XII 29-30. La costumbre de comer echados, y no sentados, entra en Grecia por influjo oriental hacia el siglo VII a. C., como forma del banquete de la aristocracia. En este sentido, J. Boardman (1990: 124) hace notar que en la época anterior, en el periodo geométrico, no hay evidencias en el arte de que se usaran los lechos para comer. Sobre el paso del banquete homérico al sympósion cf. Murray 1983a, 1983b y 1990: 6-7; Musti 2001: 19-20.

6 Burns 1970: 54. van Wees 1995: 155-156. Burton 1998: 144-145. Rundin (1996: 189-190) hace notar que en realidad son dos casos anómalos, el de Arete probablemente por las propias características del pueblo de los feacios, más cercanos a los dioses que a los hombres mortales, y el de Helena por su condición de hija de Zeus. También M. B. Arthur (1984: 18-19) es de esta opinión y considera que no dan información sobre el papel de la mujer en esta época. 
al menos, como señalan Rundin y Colesanti (Rundin 1996: 190. Colesanti 1999: 52), no hay pasajes que lo afirmen o permitan suponerlo. Por otra parte, no se mezclan con los hombres, sino que intervienen en la conversación manteniéndose a cierta distancia, acompañadas de sus criadas y dedicadas al hilado de la lana7. Hay que señalar además que todo apunta a que en el banquete sólo hay una posición reservada para la mujer, la de la señora de la casa. No hay referencias a las esposas de los invitados, que se quedan en casa, y la historia de Nausícaa muestra que las hijas solteras también estaban excluidas del banquete ${ }^{8}$, aunque no del consumo de la bebida, puesto que, cuando sale a hacer la colada junto a la orilla del mar, donde se encontrará con Ulises náufrago, entre las provisiones que le prepara su madre se encuentra un odre de cabra lleno de vino (Od. VI 76-78).

En esta segunda parte del banquete, separada de la primera por el verso formular, es cuando se distribuye la bebida y sólo entonces Homero hace referencia a la presencia de cantos y danzas, que tampoco faltan en los banquetes de los dioses, amenizados por Apolo y las Musas ${ }^{9}$. En esta versión primitiva del simposio el vino ya se consume rebajado, según la práctica común en épocas posteriores; de hecho, son frecuentes las alusiones a la cratera, el recipiente propio para la mezcla, y a la acción de preparar la bebida ${ }^{10}$. Sólo muy raramente se cita de forma explícita el agua (cf. Od. I 110-111), aunque podemos suponer con cierta seguridad que también se emplea en los demás casos en los que se hace referencia a esta operación. Son variados los personajes que pueden llevarla a cabo: a veces son los heraldos o una criada ${ }^{11}$; en otras ocasiones es el propio anfitrión o una persona muy próxima a él, como Andrómaca, que prepara la bebida para los huéspedes de Héctor, o Patroclo para los de Aquiles ${ }^{12}$. En este último pasaje se habla de una mezcla "más fuerte», pero Homero no indica casi nunca las proporciones, lo que sólo empezará a encontrarse a partir de Hesíodo (Los trabajos y los días 596) y sobre todo en la poesía lírica y en la comedia ${ }^{13}$. La única excepción aparece en la Odisea IX 208-210, donde se describe la preparación del prodigioso vino de İsmaros, tan fuerte que debe ser mezclado con veinte partes de agua.

Mientras beben, los participantes pueden simplemente pasar un rato de entretenimiento amenizado por el relato de un huésped o por el canto de un citaredo, pero también puede ser un momento importante para la toma de decisiones. Dos buenos ejemplos de ello se encuentran en el canto IX de la Ilíada, en dos escenas relacionadas entre sí. La primera de ellas tiene lugar en el alojamiento de Agamenón, donde los jefes aqueos se han reunido a instancias de Néstor. Sólo después del mencionado verso formular (92), cuando llega el momento de la bebida, éste, tras exponer la situación en que se encuentran, propone a Agamenón que haga las paces con Aquiles (96-113). Él accede inmediatamente y el compromiso que asume queda sacralizado por una libación en honor de Zeus (171-178). La segunda escena es en cierto modo la continuación de ésta: los heraldos designados, Fénix, Ulises y Ayante, acuden a la tienda del héroe para convencerlo de que vuelva al combate. Él los recibe con la acostumbrada hospitalidad homérica, ofreciéndoles un festín a base de carne asada de cabra, oveja y cerdo (199-220), y sólo abordarán el asunto que los ha llevado alli «después de haber saciado el deseo de comida y bebidan. Los discursos entre los cuatro héroes se abren con un brindis de Ulises en honor del anfitrión (223-225) y se cierran con una libación (656-657).

A lo largo de los poemas son varias las ocasiones en que aparecen libaciones en el marco del banquete, siempre con vino mezclado. Con ellas se inicia el festín y se abre la parte dedicada a la bebida, pero una última libación precede también la retirada de los comensales ${ }^{14}$. En este momento se encuentran los feacios cuando Ulises Ilega al palacio de Alcínoo en el canto VII de la Odisea; según su costumbre van a ofrecer una a Hermes antes de retirarse, pero la sustituyen, en consideración al héroe, por otra a Zeus, patrón de los forasteros (136-138. Cf. II. IX 712; Od. XVIII 423-428).

El vino tiene también un valor sacral muy fuerte, porque acompaña plegarias y juramentos. Este segundo caso se puede ver en el canto III de la Ilíada, en el pasaje en el que Príamo y Agamenón sellan un pacto que resolverá la guerra por medio de una lucha singular entre Menelao y Paris (245301. Cf. Od. XIX 288). Los heraldos Ilevan dos corderos como víctimas sacrificiales, además de un odre de piel de cabra con vino, una cratera y dos tazas de oro. Antes del momento del sacrificio, se mezcla el vino en la cratera y se vierte agua sobre las manos de los reyes, como purificación previa. Una vez que Agamenón ha invocado a los dioses como garantes de los pactos y ha sacrificado los corderos, se llevan a cabo las libaciones, con invocaciones e imprecaciones contra los posibles perjuros. Otra escena particularmente solemne, en este caso de plegaria, precede la entrada de Patroclo en el combate (II. XVI 220-254), momento en que Aquiles hace una li-

Od. I 330-331, 334-335, IV 119-122, 136-137, VI 303-309, XVII 96-97, XVIII 207, 210-211, XXI 63-66.

${ }^{8}$ Cf. van Wees 1995: 156-158. Cf. Od. VIII 456-458.

9 II. | 469-473; Od. I 150-152, 325-326, IV 17-20, VIII 72-73.

De la antigüedad de esta costumbre en la cultura griega da una idea el hecho de que el nombre de la cratera, $k a-r a-t e-r a$, aparece documentado ya en las tablillas micénicas escritas en Lineal B encontradas en Micenas (MY Ue 611).

II. III 268-270; Od. I 110, VII 165-166, 179, XIII 50

12 Od. III 332, XIV 78; II. VIII 189, IX 202-204.

13 Alceo, fr. 346 Voigt. Anacreonte frr. 24 y 33 Gentili. Aristófanes, Caballeros 1187, Riqueza 1132. Ferécrates, fr. 76 K.-A. Cratino, fr. 196 K.-A. Eupolis, fr. 6 K.-A. Arquipo, fr. 2 K.-A. Timocles, fr. 22 K.-A. Alexis, frr. 59, 228 y 232 K.-A. Jenarco, fr. 9 K.-A. Diocles Cómico, fr. 7 K.-A. Nicócares, frr. 2 y 16 K.-A. Amipsias, fr. 4 K.-A. Hermipo, fr. 24 K.-A. Filetero, fr. 15 K.-A. Efipo, fr. 11 K.-A.

14 II. VII 480-482, XI 656-658, 712-713; Od. III 333-334, XIV 446. Cf. Plutarco, Obras morales 714c. 
bación en honor a Zeus pidiendo que los troyanos sean rechazados y que su amigo regrese sano y salvo, lo que, como sabemos, no sucederá.

Estos ofrecimientos de vino a los dioses son particularmente importantes cuando se va a emprender una tarea difícil, como cuando Príamo va a reclamar el cadáver de Héctor a Aquiles o cuando Telémaco emprende la navegación para averiguar qué le ha ocurrido a su padre ${ }^{15}$. Más fuerte aún es el significado sacral del vino en los contextos funerarios, de los que los poemas ofrecen tres ejemplos muy importantes. En la llíada éste es el líquido con el que se apagan las piras funerarias de dos héroes de primera línea, Patroclo y Héctor; en la Odisea los aqueos recogen los huesos de Aquiles y los limpian con grasa y vino purísimo ${ }^{16}$.

Junto a su valor simbólico y sacral se le reconoce también un alto valor nutritivo, por lo que se da incluso a los niños, como le recuerda Fénix a Aquiles que hacía con él cuando era pequeño (II. IX 489-491). Por ello se propone como bebida fortificante en las situaciones difíciles, por ejemplo antes de entrar en combate, porque en la comida y la bebida están la fuerza y el coraje (II. IX 706). Así, Ulises aconseja a Aquiles que levante la moral de las tropas dándoles de comer y de beber: el guerrero que ha recibido bastante vino y alimento tiene un corazón valeroso y no se resiente del esfuerzo (II. XIX 160-170). Por el mismo motivo Hécuba, la madre de Héctor, en un descanso de los combates le exhorta a que beba vino, porque "aumenta mucho el vigor al hombre que está exhausto de fatigan. Su hijo, sin embargo, lo rechaza por temor a que se relaje su ímpetu y le abandone el coraje (II. VI 261-265). Se encuentra así mismo entre las provisiones que Telémaco lleva consigo cuando parte de Ítaca para buscar noticias de su padre y entre las que Néstor le proporciona para su viaje a Esparta, cuando le aconseja que vaya a visitar a Menelao ${ }^{17}$.

Aparte de los aspectos relacionados con el consumo y los usos rituales del vino, Homero presta atención también a las circunstancias en que se produce, ofreciendo las primeras informaciones en la literatura griega sobre el cultivo de la vid y la vendimia, que aparecen representados en la superficie del escudo que el dios Hefesto realiza para Aquiles (II. XVIII 561-572). Entre las varias escenas que componen su decoración, el poeta describe una viña cargada de racimos negros, apoyada en estacas, y el regreso de los vendimiadores entre cantos y danzas con cestas trenzadas Ilenas de uva ${ }^{18}$. No faltan tampoco las vides en el jardín del rey Alcínoo, que producen frutos que maduran con distintos ritmos, de tal manera que, mientras unos racimos todavía están empezando a formarse, otros se están vendimiando y otros están ya en el lagar (Od. VII 122-126).

El poeta hace también referencia a las caracteristicas del vino, especialmente en la Odisea, que ofrece una adjetivación más rica, con alusiones a su color, a su sabor e incluso a su edad. Las primeras son menos frecuentes, aunque coinciden en apuntar al tinto como su color por excelencia. Aparece acompañado del adjetivo erythrós, «rojo», principalmente en la Odisea ${ }^{19}$, mientras que en la llíada se encuentra sólo una vez y aplicado no al vino sino al néctar de los dioses (XIX 38. Cf. Od. V 93). También en este poema aparece caracterizado como mélas, «negro», pero sólo en cuatro ocasiones y con relación a dos caldos excepcionales: uno es el que regala la ninfa Calipso a Ulises en el momento de partir de su isla y el otro es el de Ísmaros, con el que el héroe emborracha al Cíclope ${ }^{20}$. P. Vivante (1982: 18) ha interpretado esta calificación en el sentido de que se trata de un vino sin mezclar, que no ha sido diluido con agua. Lo cierto, sin embargo, es que en la literatura griega «negro» es el adjetivo normal para el tinto, independientemente de su pureza, mientras que "rojo" se encuentra en muy raras ocasiones fuera de Homero: lo usan el poeta Arquíloco (fr. 4, 6-9 West) y el filósofo Clearco de Solos (fr. 96 Wehrli), que curiosamente lo presenta como color característico del vino, al igual que blanco es el de la leche, verde el del aceite y negro el de zumo de mora ${ }^{21}$. Con más frecuencia en los poemas homéricos aparece también otro adjetivo que plantea algunos problemas de interpretación, aîthops ${ }^{22}$, que tiene su base en el nombre de la llama, aîthos. Por este motivo en ocasiones aparece entendido como "con reflejos de fuego", lo que podría representar alguna alusión al color, aunque también se ha interpretado como "chispeante», "brillante», e incluso "ardiente», por sus efectos (Garzón Díaz 1979: 71).

En cuanto a su paladar, los epitetos más usuales destacan la suavidad y la dulzura. En ocasiones se indica simple-

\footnotetext{
5 II. XXIV 284-285; Od. II 432.

16 II. XXIII 236-238, XXIV 791; Od. XXIV 71-73

Od. II 349-360, III 478-480.

${ }^{18} \mathrm{~V}$. Andò (2004: 87) ha llamado la atención sobre el hecho de que en la decoración del escudo aparece también una representación de consumo del vino ajena al ámbito del banquete (II. XVIII 541-546). Homero describe a unos agricultores que aran un campo y, al llegar al final, reciben de un hombre que les espera una copa de vino, no se sabe si como estímulo y alivio de la fatiga o como recompensa. Esta representación queda claramente aparte de la cultura heroica del resto del poema y se acercaría, en cambio, al ambiente que describe Hesíodo en Los trabajos y los dias 589-597, donde forma parte de la comida que consume el agricultor en el descanso de sus tareas.

19 V 165, IX 163, 208, XII 19, 327, XII 69, XVI 444.

20 Od. V 265, IX 195, 205, 346.

${ }^{21}$ El propio vino sirve también como punto de referencia para indicar el color del mar, repetidamente calificado como "vinoso ponto" (II. II 613, V 771, VII 88, XXIII 143, 316; Od. I 183, II 421, III 286, IV 474, V 132, 349, VI 170, VII 250, XII 388, XIX 172, 274), y también de unos bueyes, en II. XIII 703 y Od. XIII 32.

22 II. | 462, IV 259, V 341, VI 266, XI 775, XIV 5, XVI 226, 230, XXIV 641; Od. II 57, III 459, VII 295, IX 360, XII 19, XIII 8, XIV 447, XV 500, XVI 14, XVII 536, XIX 197, XXIV 364
} 
mente que es «agradable» (hedýs) y otras veces que es «agradable de bebern (hedýpotos); también se dice de él que es "dulce como la miel» (meliedés, melíphron), la caracterización que aparece con más frecuencia en los poemas ${ }^{23}$. Sin embargo, sólo en una ocasión (Od. XIV 194) se emplea un adjetivo que indica específicamente el sabor "dulce», glykerón, y además no acompaña al nombre específico del vino, oînos, sino a méthy, un término que tiene un sentido más cercano al de bebida alcohólica en general y que en origen con mucha probabilidad -según indica la comparación con otras lenguas indoeuropeas- se daba al hidromiel, aunque Homero utiliza los dos como sinónimos ${ }^{24}$.

Este sabor tiene una relación directa con el sistema de vinificación utilizado por los antiguos o, más exactamente, con el estado de los racimos que se empleaban para elaborar el vino. Una práctica muy común consistía en utilizar la uva pasificada, lo que permitía elevar el contenido de azúcar de sus granos. Este procedimiento se encuentra ya descrito en Hesíodo (Los trabajos y los dias 611-61425), que recomienda una vendimia tardía, dejando además los racimos a la intemperie durante seis días y seis noches. También puede verse reflejado de forma indirecta en la descripción del jardín del rey de los feacios en la Odisea (VII 122-124), ya que junto a la viña existe un secadero en una explanada donde da el sol. Según H. Wilson (2003: 170-171), el motivo de esta práctica tiene que ver con el proceso de envejecimiento del vino. Sostiene esta estudiosa que, en las circunstancias normales en el ámbito mediterráneo, el clima caluroso acelera la velocidad de fermentación, puesto que en la Antigüedad no se conocian bien los sistemas para controlar la temperatura que ayudarian a regularla. Recurriendo al pasificado de la uva, los griegos aumentaban la concentración de azúcar en el mosto, que las levaduras no eran capaces de convertir en alcohol en su totalidad, porque al llegar a $15^{\circ}$ sus células se destruyen. De esta manera resultaba un vino con una alta graduación y a la vez con un elevado contenido natural de azúcar, factor que ayuda a su conservación y, en opinión de esta autora, probablemente también a su evolución con la edad.

De hecho, una característica particular de los mejores vinos en Homero, presentados como si se trataran de pre- ciados tesoros, es haber pasado un largo periodo de envejecimiento. Como muestra de gran honor, Néstor recibe a Telémaco destapando un vino generoso, guardado celosamente durante once años (Od. III 391-392). Y en la casa de Ulises, en la misma cámara donde se almacenaban sus tesoros, "donde estaban el oro a montones y el bronce / y vestidos sin cuento en las arcas y aromático aceite», pegadas a la pared había unas grandes tinajas de caldo añejo que se reservaban en espera del regreso del héroe (Od. II 340-343). El aprecio por el vino que ha tenido un largo tiempo de maduración continúa a lo largo de toda la Antigüedad, como se puede ver reflejado en la poesía lírica y en particular en la comedia, donde se pone con frecuencia de manifiesto el enorme placer que proporciona cuando ha sido suavizado por muchos años de envejecimiento ${ }^{26}$. Si analizamos los testimonios que describen las características de los mejores caldos a lo largo de la Antigüedad, veremos que coinciden en buena medida con los criterios de Homero. Los más alabados son los tintos aromáticos, densos y, sobre todo, envejecidos, características en las que encajaban bien los de Tasos, Lesbos y Quíos, que en la época clásica ocupaban la primera posición por su altísima calidad ${ }^{27}$.

Ninguno de estos lugares aparece citado en los poemas homéricos como zona vitivinícola, aunque no faltan las menciones a diversas regiones ricas en vides y sobre el comercio del vino. Entre ellas, se citan Arne en Beocia, Histiea en la isla de Eubea, Epidauro en la Argólide, Pédaso en las proximidades de Pilo, Calidón en Etolia y Frigia ${ }^{28}$. Incluso en Ítaca, una isla áspera y no muy grande, se cultivaban trigo y viñedos para vino ${ }^{29}$. Sin embargo, referencias más detaIladas aparecen sólo de dos lugares, la isla de Lemnos y Tracia, de donde Agamenón recibía vino a diario (II. IX 71-72), y en esta región particularmente Ísmaros, de donde procedía del tinto de aroma incomparable, regalo de Marón a Ulises, con el que el héroe emborrachó al Cíclope (Od. IX 196-211, 347-359). El vino de Lemnos Ilegaba en naves a los aqueos que están asediando Troya y Homero en este caso incluso alude de forma explícita a su comercio, cuando afirma que "de él compraron los aqueos, de melenuda cabellera, / unos con bronce, otros con fogueado hierro, / otros

${ }^{23}$ Meliedés: II. IV 346, VI 258, X 579, XII 320, XVIII 545; Od. III 46, IX 208, XIV 78, XVI 52, XVII 151, XVIII 426, XXI 298. Meliphron: II. VI 264, VIII 506, 546, XXIV 284; Od. VII 182, X 356, XIII 53, XV 148. Cf. Garzón Díaz 1979: 71; Arnould 2002: 8.

24 II. IX 469; Od. IV 746, VII 179, 265, IX 9, 45, 557, X 162, 184, 468, 477, XII 30, 362, XIII 50, XVII 533. Cf. Chantraine 1968: 676; Sherratt 2004: 202-203.

${ }^{25}$ Cf. Catón, Agricultura 112, 2; Plinio el Viejo, XIV 77, 81, 84; Columela, XII 27, 37, 39, 1.

${ }^{26}$ Simónides, fr. 612 PMG. Pindaro, 0. IX 73-74. Alexis, frr. 172, 3-5, 280 y 284 K.-A. Eubulo, frr. 121 y 122 K.-A. Epinico, fr. 1 K.-A. Menandro Dyscolos 946.

27 Aristófanes, Asambleístas 1120, Lisistrata 195-206, Riqueza 1020-1, fr. 334 K.-A. Hermipo, fr. 77 K.-A. Alexis, fr. 276 y 277 K.-A. Clearco Cómico, fr. 5 K.-A. Batón, fr. 3 K.-A. Matrón, fr. 1, 109-110 Olson-Sens. Arquéstrato, fr. 59, 1-4, 10, $15-16$ Olson-Sens. Str. XIV 1, 35. Plinio el Viejo, XIV 73. Virgilio, Bucólicas $\vee 70$.

${ }^{28}$ II. II 508, 538, 561, III 184, IX 152, 294, 530-534, 579. En algunas de estas regiones está documentado el cultivo de la vid y la elaboración de vino en la Edad del Bronce, a través de testimonios arqueológicos y también por los asientos de las tablillas micénicas. Según R. Billiard (1913: 67, n. 2) desde la Edad del Bronce se cultivaba el viñedo en la ciudad beocia de Orcómeno y K. F. Vickery (1936: 53. Cf. Palmer 1994: 17) hace referencia al hallazgo de un pithos con restos de uvas en este lugar. Sobre la rica información relativa al vino que ofrecen las tablillas encontradas en Pilo, Tebas y otros centros micénicos resulta de especial interés el estudio de R. Palmer (1994).

29 Od. I 193, XI 193, XIII 244, XXIV 339-344. 
con bovinas pieles, otros con las propias vacas vivas, / y otros con esclavos" (II. VII 467-475).

En cuanto al de Ísmaros, Homero deja muy claro que se trata de un vino absolutamente fuera de lo común, descrito por Ulises como theîon potón, "bebida divina» (Od. IX 205). Es el regalo que Marón hace al héroe, porque, al saquear su ciudad, la primera en su camino tras abandonar Troya, lo respetó a él y a su familia por consideración a su condición de sacerdote de Apolo (Od. IX 204-211). Al presentarlo insiste en unos rasgos que llegan a hacerlo casi sagrado: era custodiado como un tesoro, de cuya existencia tenían conocimiento sólo la mujer de Marón y su despensera, y va a ser regalado a cambio de la vida. También sus propias características rozan lo sobrenatural, puesto que era tan fuerte que para poder consumirlo había que mezclarlo con veinte partes de agua y aún así exhalaba un aroma divino, que hacía difícil dejar de beber (Od. IX 195-211). Tal es el vino que salvará más tarde otra vida, la de Ulises, que con él emborracha al Cíclope, escapando así de una muerte segura. Éste, apenas lo prueba, lo califica como, "efluvio de ambrosía y néctar» (Od. IX 359), iniciando una comparación con los alimentos de los dioses que será después muy frecuente en la literatura griega ${ }^{30}$.

Con estas alusiones Homero pone de relieve el papel que ya desde antiguo tenía la zona septentrional del Egeo por su producción vinícola, de donde todavía en época clásica procedían algunos de los mejores vinos. Las alusiones homéricas se ven confirmadas por otras fuentes: en monedas del siglo $\mathrm{V}$ a. $\mathrm{C}$. de Maronea y Abdera se encuentran representados racimos, Píndaro canta a Tracia como «tierra de abundantes uvas y buenos frutos", en un peán en el que celebra a la ciudad de Abdera, y Ateneo de Náucratis, a finales del siglo II d. C., afirma que toda la región y las zonas próximas producían buenos caldos ${ }^{31}$.

Otro vino notable, pero sin localización geográfica específica, es el pramnio, el que la maga Circe utiliza para la poción con la que convierte a los compañeros de Ulises en cerdos y el mismo que Néstor ofrece a Macaón como base de una bebida reconstituyente, mezclado con queso de cabra rallado y harina de cebada32. Se trata probablemente del vino con una historia más larga, puesto que aparece con frecuencia en las fuentes literarias a lo largo de toda la Antigüedad y, según el testimonio de Plinio el Viejo, era conocido todavía en su época. Son muchas las dudas sobre su lugar de origen, ya que existían variedades de pramnio en diversos lugares de la costa de Asia Menor; con todo, hay tendencia a asociarlo con la isla de Icaria, en el archipiélago de las Espórades orientales, aunque no antes de comienzos del siglo IV a. C., cuando adquirió su reputación como región vinícola (García Soler 1999: 399-401). Tampoco hay acuerdo sobre sus características, ya que Homero lo describe como denso y nutritivo, mientras que posteriormente algunos autores señalan que era "seco y duro y con una fuerza extraordinaria» ${ }^{33}$.

A lo largo de los poemas los aspectos positivos del vino se combinan con una faceta negativa, la relacionada con la embriaguez. Los guerreros de Homero son presa de muchas pasiones, pero desdeñan siempre la ebriedad. No puede decirse que existiera ya una regulación en los banquetes como la que se aprecia en la época arcaica y más adelante, pero queda siempre muy claro que el borracho estaba mal visto. El exceso en la bebida hace cantar y hablar más de la cuenta, vuelve desvergonzado al que lo bebe, hace llorar y turba la mente cuando se toma sin medida ${ }^{34}$. Esta consideración negativa respecto al exceso se refleja también en el hecho de que uno de los insultos más graves que se pueden echar en cara a alguien es decirle que ha bebido, especialmente cuando no lo ha hecho, comparando su comportamiento con el de un borracho (Od. XVIII 331, 391, XXI 293). Esto lo sabe muy bien Aquiles cuando se dirige a Agamenón y le increpa diciéndole: "Lleno de vino, que tienes ojos de perro y corazón de ciervon (II. I 225).

Homero ofrece además varios ejemplos de las funestas consecuencias del consumo excesivo del vino. Una de sus víctimas es Elpenor, el más joven de los compañeros de Ulises, descrito por el poeta como un guerrero poco efectivo y un poco simple, que la víspera de partir de la isla de Circe se emborrachó y se subió al tejado; cuando al día siguiente lo llamaron sus compañeros, murió rompiéndose el cuello al caer desde alli por no recordar dónde estaba (Od. X 552-560). Cuando Ulises se lo encuentra en el reino de los muertos, Elpenor afirma con pesar: "Me perdieron mi suerte fatal y el exceso de vino" (Od. XI 61). Diferente es el caso del cíclope Polifemo, que toma el vino puro sin mezclar, se emborracha y además lo hace sin compañía, representando el perfecto contramodelo de lo que es el comportamiento civilizado en la bebida. Como Elpenor, también él es consciente de los efectos del abuso del vino, que considera la causa de su ceguera $(O d$. IX 454, 516). Otro ejemplo ajeno al mundo humano es el del centauro Euritión, que se emborrachó en las bodas de Pirítoo y murió víctima de la locura que la bebida le infundió (Od. XXI 297-304).

Las numerosas y variadas ocasiones en que Homero menciona el vino muestran el importante papel que ya debía

\footnotetext{
30 Aristófanes, Acarnienses 194-6, fr. 688 K.-A. Eubulo, fr. 121 K.-A. Alexis, fr. 124 K.-A. Teócrito, Idilios VII 153. Calimaco, fr. 399 Pfeiffer.

31 Píndaro, fr. 52b, 25 Snell-Maehler. Ateneo de Náucratis, I 31b. Hesiquio (s.v. Ísmaros) y el Léxico Suda (s.v. Ismarikòs oînos) identifican Maronea con la antigua İsmaros, si bien Estrabón (VII fr. 43-43a) se refiere a las dos como ciudades diferentes, aunque muy próximas. Según Plinio (XIV 53-54) el vino de Maronea -que identifica sin duda con la Ísmaros de Homero- todavía en su época era notable por su vigor y su fuerza, que obligaban a diluirlo más de lo usual.

32 Od. X 234-6. II. XI 623-643.

33 Epárquides, FGH 437 fr. 1. Cf. Aristófanes, frr. 334 y 688 K.-A.; Ateneo de Náucratis, I 30b-c; Hesiquio, s.v. Prámnios.
}

34 Od. XIV 463-466, XVIII 331, 391, XIX 122, XXI 293-294. Cf. Garzón Díaz 1979: 70; Arnould 2002: 8-9. 
de tener en la vida de los griegos al menos desde el siglo VIII a. C. Forma parte esencial del banquete, en el que se despliega la hospitalidad heroica, se estrechan las relaciones sociales o se tratan asuntos bélicos y políticos importantes. Sirve para fortalecer el cuerpo y el alma, para vigorizar los miembros y excitar el valor en el combate, pero también tie- ne una fuerte carga simbólica en el contexto de la sociedad heroica, fuertemente jerarquizada y, a través de la libación, actúa como elemento de comunicación entre los dioses y los hombres. Aparece así como un elemento fundamental del mundo homérico, como lo será también para los griegos a lo largo de toda la Antigüedad.

\section{BIBLIOGRAFÍA}

Alonso Troncoso, V., 1993: Para una sociología del banquete en los poemas homéricos. En J. Mangas y J. Alvar (eds.): Homenaje a José M. ${ }^{a}$ Blázquez, vol. I. Ediciones Clásicas, 35-58.

ANDò, V., 2004: Vino e sistema di valori nei poemi omerici. Thalassa. Genti e culture del Mediterraneo antico I, 87-99.

ARnould, D., 2002: Du bon usage du vin chez Homère et dans la poésie archaïque. En J. Jouanna y L. Villard (eds.): Vin et santé en Grèce ancienne. Actes du colloque organisé à l'Université de Rouen et à Paris. De Boccard, 7-10.

ARThUR, M. B., 1984: Early Greece: The Origins of the Western Attitude toward Women. En J. Peradotto y J. P. Sullivan (eds.), Women in the Ancient World: The Arethusa Papers. State University of New York Press, 7-58.

BIANCA, L. della, 2002: L'etica del vino. En L. della Bianca y S. Beta: OlNOS. II vino nella letteratura greca. Carocci, 27-42.

BIELOHLAWEK, K., 1940: Gastmahls-und Symposionslehren bei griechischen Dichtern (von Homer bis zur Theognissammlung und Kritias). Wiener Studien LVIII, 11-30.

BILLIARD, R., 1913: La vigne dans l'Antiquité. Lardanchet (reimpr. 1997, Editions Jeanne Laffitte).

BoARDMAN, J., 1990: Symposion Furniture. En 0. Murray (ed.): Sympotica. A Symposium on the Symposion. Clarendom Press, 122-131.

BuRNS, G., 1970: Küchenwesen und Mahlzeiten. Archaeologia Homerica Q. Vandenhoeck y Ruprecht.

BURTON, J., 1988: Women's Commensality in the Ancient Greek World. Greece \&t Rome XLV, 2, 143-165.

CARLIER, P., 1984: La royauté en Grèce avant Alexandre. AECR.

ChANTRAINE, P., 1968: Dictionnaire Étymologique de la Langue Grecque: Histoire des Mots. Klincksieck.

ColesAntI, G., 1999: II simposio in Omero. Materiali e discussioni per l'analisi dei testi classici XLIII, 41-75.

DALBY, A., 1996: Siren Feasts. A History of Food and Gastronomy in Greece. Routledge.

Garcia Soler, M. J., 1999: Algunos nombres de vinos en griego antiguo. Habis XXX, 389-401.

Garzón Díaz, J., 1979: Vino y banquete desde Homero a Anacreonte, Helmantica XCl, 63-96 (esp. 63-72).
MAINARDI, G. y BERTA, P., 1991: I/ vino nella storia e nella letteratura. Edagricole.

MurRaY, 0., 1983a: The Greek Symposium in History. En E. Gabba (ed.): Tria corda. Scritti in onore di Arnaldo Momigliano. New Press (Biblioteca di Athenaeum, 1), 257-272.

- 1983b: The Symposium as Social Organisation. En R. Hägg y N. Marinatos (eds.): The Greek Renaissance of the Eight Century B. C.: Tradition and Innovation. Proceedings of the 2 nd International Symposium at the Swedish Institute in Athens, 1-5 June 1981. Åström, 195-199.

- 1990: Sympotic History. En O. Murray (ed.): Sympotica. A Symposium on the Symposion. Clarendom Press, 3-13.

Musti, D., 2001: / simposio nel suo sviluppo storico, Laterza Editori.

Palmer, R., 1994: Wine in the Mycenaean Palace Economy. Université di Liège - The University of Texas at Austin.

RundiN, J., 1996: A Politics of Eating: Feasting in Early Greek Society. The American Journal of Philology CXVII, 2, 179-215.

SherRatr, S., 2004: Feasting in Homeric Epic. En J. C. Wright (ed.): The Mycenaean Feast. American School of Classical Studies at Athens, 181-217. Publicado también en Hesperia LXXIII, 2, 2004, 301-337.

van WeEs, H., 1995: Princes at Dinner: Social Event and Social Structure in Homer. En J. P. Crielaard (ed.): Homeric Questions. Essays in Philology, Ancient History and Archaeology, including the papers of a conference organized by the Netherlands Institute at Athens (15 May 1993). Gieben, 147-182.

VETTA, M., 1995: Poesia simposiale nella Grecia arcaica e classica. En M. Vetta (ed.): Poesia e simposio nella Grecia antica. Guida storica e critica. Editori Laterza, xi-Ix.

- 1996: La cultura del simposio. En J.-L. Flandrin y M. Montanari (eds.): Storia dell'alimentazione. Editori Laterza, 124-134.

VICKERY, K. F., 1936: Food in early Greece, Ares Publishers Inc.

VIVANTE, P., 1982: The Syntax of Homer's Epithets of Wine. Glotta LX, 13-23.

VON DER MüHL, P., 1975: Das griechische Symposion. En P. von der Mühl: Ausgewählte kleine Schriften. F. Reinhardt, 483-505.

W CowsKI, M., 2002: Homer and the Origins of the Symposion. En F. Montanari (ed.): Omero tremila anni dopo. Atti del Congresso di Genova, 6-8 luglio 2000. Edizioni di Storia e Letteratura, 627-637.

WILSON, H., 2003: Wine and Words in Classical Antiquity and the Middle Ages. Duckworth. 
